\title{
LOCAL ORGANIZATIONS: VIABLE MECHANISM FOR ENSURING PARTICIPATION IN RURAL DEVELOPMENT
}

\author{
Pashupati Nepal
}

\begin{abstract}
Local organization was overlooked in development theories for a long time mainly because of the technocratic understanding of development. But this situation did not exit for a long time. Development planners began to search the causes of unsatisfactory result of past development strategies and formulated new strategies that enhance local organized efforts. The organizations lie beyond the government play active role in rural development relative to government organization. Local organization is an important mechanism for involving people in rural development. The most essential local resource in any development activities is the people themselves who, along with their mutual cooperation, transform shapeless materials into useful commodities using skills, intelligence and labour. People can influence the decisions through their joint efforts and common voice. Organization provides ownership to local people in development activities and ensures fair share of benefits. In this context, this article aims to analyze local organizations as viable mechanisms for insuring participation in rural development.
\end{abstract}

\section{INTRODUCTION}

The most serious drawback in conventional strategy for rural development in many developing countries including Nepal has been the centralized decision making process in which, development decisions are taken centrally and imposed locally for only implementation without considering spatial, geo-economic conditions and socio-cultural values. The disenchantment of past strategy to rural development-planning process seeks full participation and initiation of local people- the beneficiaries. Such participation requires for accomplishing broad-based rural development and sustaining such participation requires some sorts of collective organizations that are accountable and responsive to their members, needs.

It is now widely recognized that the access of physical, technical and financial resources is not a sufficient condition for rural development. The strength and weaknesses of organizational set-up as well as behavioral factor play a significant role in determining the nature and pace of the development process (Narayansuwami, 1991). In many cases, both the government organizations (GOs) and locally initiated non-government organizations (NGOs) undertake similar developmental activities, while in case of the former, the grass root organizations seemed to play the role of passive recipient, in case of the latter, the organization increasingly play an active role in every stage of planning processes relating to rural development activities (Shams, 1987).

Mr. Nepal is Associated Professor in Geography at Tribhuvan Multiple Campus, Tansen, Palpa, Nepal. 
LOCAL ORGANIZATIONS: VIABLE MECHANISM...

In essence, this article is basically concentrated to analyze Local Organizations (LOs) that lie beyond the government and are involved in development activities. However, it attempts to review the position of local organizations in development theories and presents some conceptual aspects of Local Organizations. Besides, it also discusses about LOs as viable mechanisms for ensuring participation of people in rural development.

\section{LOCAL ORGANIZATIONS IN DEVELOPMENT THEORY}

\section{MODERNIZATION AND THE IDEA OF TRICKLE DOWN}

Since 1950s both development planners and most of third world leaders have regarded modernization in the sense of development. Moreover, transformation of 'traditional' values into 'modern' ones was understood as development. The development countries in the third world should, therefore, follow the stages of development as they were given by the so-called developed countries. It was the model of industrial development worked out by Rostow. Likewise, the Lewisian model assumed that the surplus generated by the industrial sector would 'trickle down' to the rural areas and reduce the backlog of rural surplus labour in the industrial sector through the stimulus of marginally higher wage rate. The assumption inherent in this model is that huge investments in the rural development would promote economic growth in rural areas and the overall benefits would then trickle down to the bottom layers of society. Rostow's nation of 'leading sector' and 'unbalanced growth' and Lewis's insistence on the importance of capital accumulation in the modern sector of the economy, for instance, provided a perfect theoretical justification for 'one sided emphasis on urban industrial development' (ESCAP, 1979). The trickle down approach, however, failed largely because accelerated per capita income alone in absolute term could not minimize the gap between the poor and the rich. Furthermore, growth-oriented paradigm of development did not result in percolation of benefits, but accelerated the existing disparities in incomes and levels of living among people. It is clear that in such a technocratic understanding of development, there was not much opportunity for the participation of local organizations of the rural population.

\section{COMMUNITY DEVELOPMENT}

Unlike the modernization theories the community development approach gave importance to the development potentialities of the rural communities. Particularly the non-governmental organizations, which stressed the importance of the participation of 'local target groups' in the process of rural development, adopted basic ideas of community development approach.

The central features of the community development approach can be summarized as follows:

- $\quad$ Establishment of a coordination team at the local level;

- Training and assignment of local community development workers as so-called change agents;

- Regular contact and dialogue between the community development team and the villagers; and

- $\quad$ Formation of local groups at the village level. 
Actually, the community development approach intended to repeat similar experiences to those derived from the modernization approaches. The approach did not provide much support to self-help activities at the village level. Decisions were still made in the centralized planning apparatus. Again, it was the local elites who benefited most from development programs. The approach neglected social stratification and conflicts of interest in the local communities and also the existing power structures of the community (Bonffgartz 1992).

\section{COMMUNITY PARTICIPATION}

The 'community participation' approach emerged from criticism of the 'community development' approach in the 1970s. It did adopt some of the principle inherent in the community development approach but tried to avoid its 'bureaucratic administration' and its 'superimposed direction'. The basic assumption underlying the community participation approach is that:

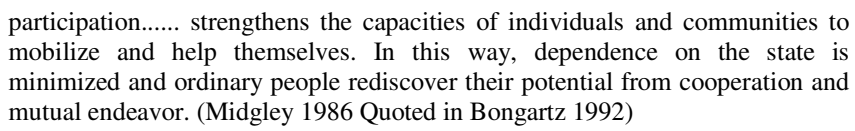

A number of questions have emerged from the community participation approach- which remained unanswered till now. First of all, who and what kind of community should participate? Secondly, what happens in a stratified society where the local power structure has an elitist bias? Thirdly, how local self-reliance can be achieved with the state having monopolized development progrmmes in most developing countries? These are the most crucial issues raised in this connection.

\section{BASIC NEEDS APPROACH}

In the 1970s, another development strategy that focused towards 'basic needs' approach, which was the result of the criticism of the 'traditional' development approaches and it put emphasis on greater equity in benefit distribution of the national development efforts. In the promotion of basic needs approaches to development at the 1976 World Employment Conference, the International Labour Organization (ILO) similarly recognized the importance of stressing the requirements of the poorest groups of people by increasing their productivity and incomes.

The issues of this concept, among other things were the call for popular participation, decentralization of planning and administration, and self-reliance at the local level to achieve these goals, popular organizations at the grass-root level had to be established and promoted, so that the effective mobilization and efficient use of local resources for development purposes can be ensured.

However, as identical with all the previous development strategies, the basic needs approach also suffered from major weaknesses of translating plans and objectives into implementation at the local level. The approach itself is not free from conflict. For instance, whose basic needs should be met first? And in the case of the poor, should it be done by redistributing the wealth of the better off or by means of state intervention? The provision of basic services remained key issue in developing countries mainly due to the lack of service receiving mechanism and capacity of mobilization of available resources efficiently at the grass root. 


\section{LOCAL ORGANIZATIONS: VIABLE MECHANISM...}

\section{SELF-HELP APPROACH}

Since 1980s, the development strategy has focused on self-help concept as a synthesis of the above mentioned development strategies. The aspects of participation in their totality get again the greatest attention, but strategies to initiate and promote participation differ from the previous concepts. The old concept of popular participation is discarded and stratification of the communities is taken into account (Bongartz, 1992)

The major thing introduced into the discussion of development concepts in the eighties was a new set of strategies about how to reach and strengthen the position of the rural poor. Instead of initiating popular participation, the need of self-help organizations that could be 'owned' and controlled by the rural poor themselves was clearly evident.

Self-help approach encourages local population to undertake certain tasks jointly, which could be more rationally performed by a group than by individuals and motivate local populations to participate actively in achieving desired goals (Kirsh et. al. 1980, Quoted in Bingartz 1992).

The proponents of self-help approach consider participation of the local population as the main factor in their development strategy. Equally, they agree that the rural poor themselves can not achieve much without external support and assistance largely because they hold limited resources (both physical and nonphysical). Hence, the scarce of resources has to be complemented by the necessary support from outside. Over the last few years, self-help approach has been achieving a number of successes. However, criticism dealing with various aspects of the self-help approach has also emerged:

Many current calls for involvement of the rural poor are little more than wishful thinking, inadequately informed by past experience as to the investment in institutional innovation required to give reality to an important idea (Korten 1980)

\section{PARTICIPATORY DEVELOPMENT APPROACH}

In 1990s, development strategy moved away to emphasize the micro foundations of development issues. For this reason, another strategy designed for development in 1990s focuses target groups-the rural poor, who are to be particularly benefited from the development. This strategy greatly emphasizes the rural people, their participation in decision- making and implementation rather than on an enclave urban sector. The target group approach emphasizes the designation of development programs from the below (bottom-up) rather than top and down model and by the people rather than for the people. Development planners and policymakers are now motivating towards micro-level decisions realizing their crucial role in local development. It is impossible without investing and empowering its people, particularly to those mechanisms, which encourage voice and participation. Without broad participation, without more human and social capital, development is unlikely to be fast and sustainable-because excluding large segments of society wastes potentially productive resources (The World Bank, 2004). For this reason, building effective organization of the rural people at the local level is becoming an urgent thrust in development strategy without which, respond to locally identified priority 
needs, and solve local problems collectively through local resource mobilization and participation remains rhetoric rather than reality.

In the Nepalese context, it can be witnessed that Nepal has been following the global current of development strategies. For instance, in Nepal, the development paradigm in 1950s and 1960s was very much influenced by periodic plan approach, which laid more emphasis in infrastructure development and economic growth. The failure of this strategy to reach the poor- led to the reorientation of development strategy from the conventional approach to 'redistribution with growth' was clearly noticed in the 1970s. The alleviation of poverty therefore, became the central focus of development in this decade. In the same decade, a comprehensive approach was developed in the form of 'Integrated Rural Development Projects (IRDPs)'. Although the IRDP induced the concept of area- based planning with better balance and complementarily between various sectors, the planning continued predominantly to be top-down proceeding from the central ministries to their line agencies based in districts. In the decade of 1980s the development strategy shifted towards 'basic needs approach' with the aim of achieving a certain specific minimum standard of living. However, it could not achieve success hoped at the time of advocation largely because of absence of receiving mechanism at the grass-root level to absorb the services delivered by government institutions. Besides, the policy makers, the bureaucrats and the technocrats, who along with the donors, decided the 'packages' of basic needs for the rural poor and then they tried to impose that package on rural population without considering the real situation. By reviewing the past development strategies and its root cause of unsatisfaction, the principle strategy of development in Nepal has been group development and group-oriented activities for over two decades, and especially since the restoration of pluralistic policy in 1990. Groups are a good vehicle for reaching people with services, strengthening resource user's groups, mobilizing multi- purpose community development, and contribute to the goals of social inclusion and empowerment of group members.

\section{ORGANIZATION AND LOCAL ORGANIZATION}

'Organization' is a 'grouping of two or more people for a specific activity of its own group to serve their community.' The group formed may have its own rules and regulations either written or unwritten as a frame- work for the groups activities. The group may be registered according to the provisions of law to retain formal status or exists as an informal group. In other words, organization refers to the rational coordination of activities by a group of individuals with the aim of achieving some common purpose (Esman \& Uphoff, 1984). Organization thus, is a structure of roles. While many institutions are organizations (e.g. households, cooperatives), many institutions are not organizations (e.g. money, the law, market) and many organizations are not institutions (e.g. a particular grass-root organization). If an organization acquires special status and legitimacy satisfying people's needs and for meeting their normative expectations over time, we can say that an organization has become institutionalized (Uphoff, 1986).

'Local Organization' is defined as 'locally based membership organization, which act on behalf of and is accountable to their membership and which is involved in development activities (Esman \& Uphoff, 1984). 'Local 


\section{LOCAL ORGANIZATIONS: VIABLE MECHANISM...}

organization' can also be defined as any locally organized entity of society that contributes to local development without aiming at generating profits for owners of the organization from the work that it does.

\section{TYPOLOGY OF LOCAL ORGANIZATIONS}

As far as the participation of the rural people in local organizations is concerned two main types of rural organizations clearly emerge: standard (government/donor sponsored) and participatory (local initiated) rural organizations (FAO, 1979). characteristics:

Standard local organizations usually have the following

- $\quad$ They are founded and sponsored by and outside mostly government agency, with a top-down approach to development for the people rather than a bottom-up approach. The idea is that benefit will trickle down from above.

- They are more formal and official.

- Their set-up often is inspiring by alien concepts, principles and policies frequently imported from abroad.

- $\quad$ They are mostly elite-oriented and/or dominated with the result that the elite benefits more than others. characteristics:

Participatory local organizations usually share the following

- $\quad$ Participatory local organizations cover only those groupings that are not organized or managed by the state. They are started by the people themselves and not by a government or other outside agency.

- $\quad$ These organizations cover a wide range of formal and informal networks and organizations including Non-government Local Organizations (NGLOs-mostly informal) Non-governmental Organizations (NGOsmostly formal) and 'Community-Based Organizations' (CEOs-mostly informal), which work in close cooperation with local people and are important vehicles facilitating the local development.

- $\quad$ They are more flexible in objectives and in set-up.

- Their leaders and their members are mainly the poor who reach decisions in face-to-face relationships.

- $\quad$ Their activities are related to the day-to-day situation and needs of the rural people. The leadership of participatory organization is selected and continued as per contribution and capacity of the members instead of imposition.

- $\quad$ They are formed and controlled by their members to a large extent and through these organizations, development activities are performed by the members themselves.

- $\quad$ These organizations distinguish them from organs of the state and also from more purely social and cultural association.

Participatory Organizations function as delivering social and developmental activities for a long time but may or may not have retained any legal status. Such organizations keep powerful presence in all communities. Contrary to it, standard organizations that they maintain registration with different Governmental Line Agencies (GLAs) and retain formal status. Such organizations hold certain defined 
rules, roles and responsibilities. As a criteria of direct involvement with development activities both standard and participatory local organizations can be categorized into three types- Membership Organizations-MOs, Cooperatives - Co-ops and Service Organizations- SOs (Esman \& Uphoff, 1984).

1. The first types, Membership Organizations (MOs) include local self-help associations whose members may seek to handle; (i) multiple tasks, e.g. local development associations or village development committees, (ii) specific tasks, e.g. water users' groups, forest users' groups etc. (iii) needs of members who have some particular characteristic or interest in common, e.g. mother's clubs, caste associations, women groups etc. Membership organizations are area-based bringing together all or most of the people within a community or village to promote its development by direct self-help. Membership in such organizations occurs heterogeneous as the communities involved, since the only common characteristic that member share is their place of residence.

2. The second type of NGLO is Service Organizations (SOs) which, include those organizations, formed primarily to help persons other than members though members may benefit from them (Examples are religious or charitable associations, service clubs, Red Cross Societies, Human Right Associations etc.). These service organizations (SOs) produce benefits for persons outside their organization, but these persons are regarded as their clients rather than as members and thus have no right to determine the activities of the organization.

3. The third type, cooperatives (Co-ops) is extremely varied and has many subtypes. One can usefully distinguish this set of LOs from the rest, however, by focusing on their economic functions and activities for their members. The most crucial difference between Co-ops and both MOs and SOs is that the former are usually of a more private nature, most accruing directly to members while the latter contribute mostly to "public goods," accessible to all. The defining characteristic of cooperative is the polling of resources by members. The resources involved include capital (savings societies or rotating credit associations), labor (rotating work groups i.e. Parma), land (production cooperatives), purchasing power (consumer co-ops), or products (marketing co-ops). A delimiting criterion between cooperatives and private business is that the former offer possibilities for increasing the productivity of economic activity and promote income of their members depending upon institutional ideology, including equality and member participation while the latter undertake production directly as their main activity and promote incomes of individuals through market mechanism.

\section{LOS: INTERFACE BETWEEN RURAL RESIDENTS AND PUBLIC SECTOR AND PRIVATE SECTOR}

Until recently, most discussions on organization focused on two sectors of the public and private ones. Recently, however, local organizations have emerged as a third sector. The growth of these intermediary organizations fulfills the need to bridge the 'missing middle' between people and the state. In other 


\section{LOCAL ORGANIZATIONS: VIABLE MECHANISM...}

words, these can act as an interface between rural residents and both government agencies and private commercial firms (fig. 1). The first i.e. public sector relies on bureaucratic mechanisms and seeks enforced compliance with government decisions, that believe on hierarchy and control. Decisions are made by experts as per to technical principles and criteria, following policy objectives set by top officials. The second i.e. private sector relies on market mechanisms and seeks to promote desired behavior through price incentives. Decisions are left to individuals, who calculate private advantage from competition. The third approach i.e. local organization relies more on voluntary mechanism, which provide voice and collectivity, appealing to people's sense of interest and values. Cooperation is sought through process of bargaining, discussion, accommodation, and persuasion. Decisions are taken with reference to both group and individual interests neither state authority nor rules of profit maximization determine choices (Esman \& Uphoff 1884). It is, therefore, beyond government there exists a large area of human organization and activity through which people collectively advance their wealth and well-being (Curtis, 1991).

Fig. 1: Showing NGLOs as Intermediary between rural people and public sector and private sector

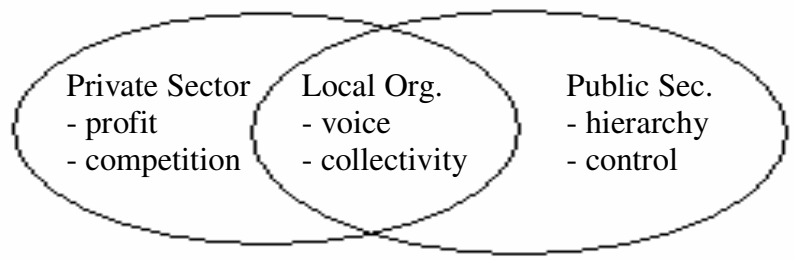

\section{POTENTIALITIES OF LOS}

LOs work in close co-operation with local people and guide community members to voluntary co-operation based upon social capital-close personal ties and mutual trust (Hayami, 2001). In fact, rural development is the true reflection of the people's needs and aspirations and the implementation of the rural development plans achieve success only if people can achieve fair-share of the fruit of development with the help of these organizations. If broad based rural development is to become a reality rather than merely a slogan, LOs building is inevitable because these organization have several potentialities:

- $\quad$ They can facilitate public services by providing government agencies with more legitimate, and accurate information on local needs, priorities and capabilities and more reliable feedback on the impact of government initiatives,

- They can promote mutual assistance by collective action,

- They can strengthen the local people, providing them the voice and capacity to make credible demands on government and others who control the resources,

- $\quad$ They can function as a 'receiving mechanism' from which they can exert pressure and make effective claims on the 'delivery mechanisms' in the public and also in the private sector to some extent,

- $\quad$ They help mobilize local resources, not only natural resources, viz., wood, stone, water, minerals, etc. but also the human resources-the local people, their culture and skills, 
- $\quad$ They facilitate in involvement of local people including the poor in all stages of development processes- planning/decision making, implementation, benefit sharing and evaluation,

- $\quad$ The benefits to the group of working together outweigh the costs,

- The group is embedded in the existing social organization,

- The group has capacity, leadership, knowledge and skills to manage the tasks,

- $\quad$ The group owns and enforces its rules and regulations.

- In terms of the functioning of the local organizations, two forms of countervailing power can be distinguished: (a) reinforcement (b) increased control over policies and practices of various development organization which distribute productive resources and services. This is termed the "claim-making power" and is related to the non-market distribution system. Increased bargaining power finds its expression in better services at the market place. Increased "claim making power" manifests itself in a greater share of resources and facilities being channeled to the rural poor, who, organized into groups, can make their voices heard effectively. The capacity of LOs to conduct these functions however depends on the degree to which responsibility for planning and management is decentralized to local units of development organizations.

\section{ATTRIBUTES OF LOS}

\section{PURPoSE AND MOTIVATION}

LOs usually have a purpose or sometimes several purposes. Purpose in either sense is an expression of the benefits which people expect to get by organizing or joining on organization. If they can acquire the right combination of benefits people are motivated to participate; any shortfall in benefits will lead to reservations about participation. Usually, irrigation and community forestry groups are formed with single purpose but credit and community development programs are often run with multiple purposes.

\section{LEGITIMACY}

The need for building such an organization thus arises when some desired innovation is not rejected and needs to be legitimized. The legitimacy takes place when support and complementarily are granted by the environment. No organization can work without some degree of acceptability or legitimacy. Social trust and rituals of understanding serve to signal the enactment of legitimacy (Curtis, 1991).

\section{Program}

This represents actions that in most cases are related to the performance of functions and services continuing the output of the LOs. Such organizations are set up in order to attain a set of common objectives. They have to formulate concrete programs of action to fulfill those objectives. Objectives, thus, are translated into a concrete set of activities through programs. Moreover, allocation of available resources over time for achieving desired outputs is the essence of programs. Organizational as well as leadership performance is judged by its members in terms of success attained in that direction. 


\section{LOCAL ORGANIZATIONS: VIABLE MECHANISM...}

\section{LEADERSHIP}

Leadership is one of the important components in organization for its role in identifying and articulation problems to be acted upon, in formulating plans of action, in mobilizing resources and managing them and in resolving conflicts. In LOs usually leaders are 'born' as per their contribution instead of 'nomination.' Leadership and participation are two sides of the same coin, though leaders and members may have different interests and needs. Without leadership, there is no sustained or sustainable participation but the reverse is equally true (Esman \& Uphoff, 1984). It is considered to be the single most critical element in organization because deliberately induced change processes require intensive, skillful, devoted, logical, foresighted, innovative and confident in both of internal and external relationships. In addition to these, if the leadership fails to manage the egos inherent in their members rationally, there may arises division between leadership and members.

\section{RESOURCES}

Resources represent the physical, human, technological and information inputs of the organization, both tangible and intangible. An organization generally is linked to its environment through various transactions whereby resources are secured as inputs form the environment and after being converted into outputs are transmitted back to it (Uphoff, 1971). People, however, are essential for the institution to operate. Generation of resources from indigenous and domestic sources is vital for an organization to become institution. The scarcity of resources necessitates making choices among alternative activities, setting priorities and arranging sequence of activities.

\section{STRUCTURE}

Organizational structure is often used instead of organizational 'form'. In addition, 'structure' may be used to express organizational set -up beyond single organizations. For instance, certain co-operatives, community organizations, etc, may be structured in hierarchical tiers - such as primary, secondary and tertiary societies. Units of one tier may be referred to as organizations with their particular form, while the full set -up of functionally interrelated bodies are referred to by the term 'structure'. Moreover, there may be formalized collaborative arrangements between more independent organizations, the sets of and functional relations between which we may also call a 'structure'. For instance, we may use this term to signify the set of and relations between formally collaborating independent organizations in a regional development program (Dale, 2004).

SIZE

The size of the organizations range from five to a few hundreds families/households depending upon the nature of the programs implemented. Usually, the largest group size is found in sectors like community forestry while small group size is found in rural credit groups.

\section{COMPOSITION}

Composition of an organization in terms of caste/ethnicity, gender, class and location of residence is an important component to steer people - based programs successfully. 


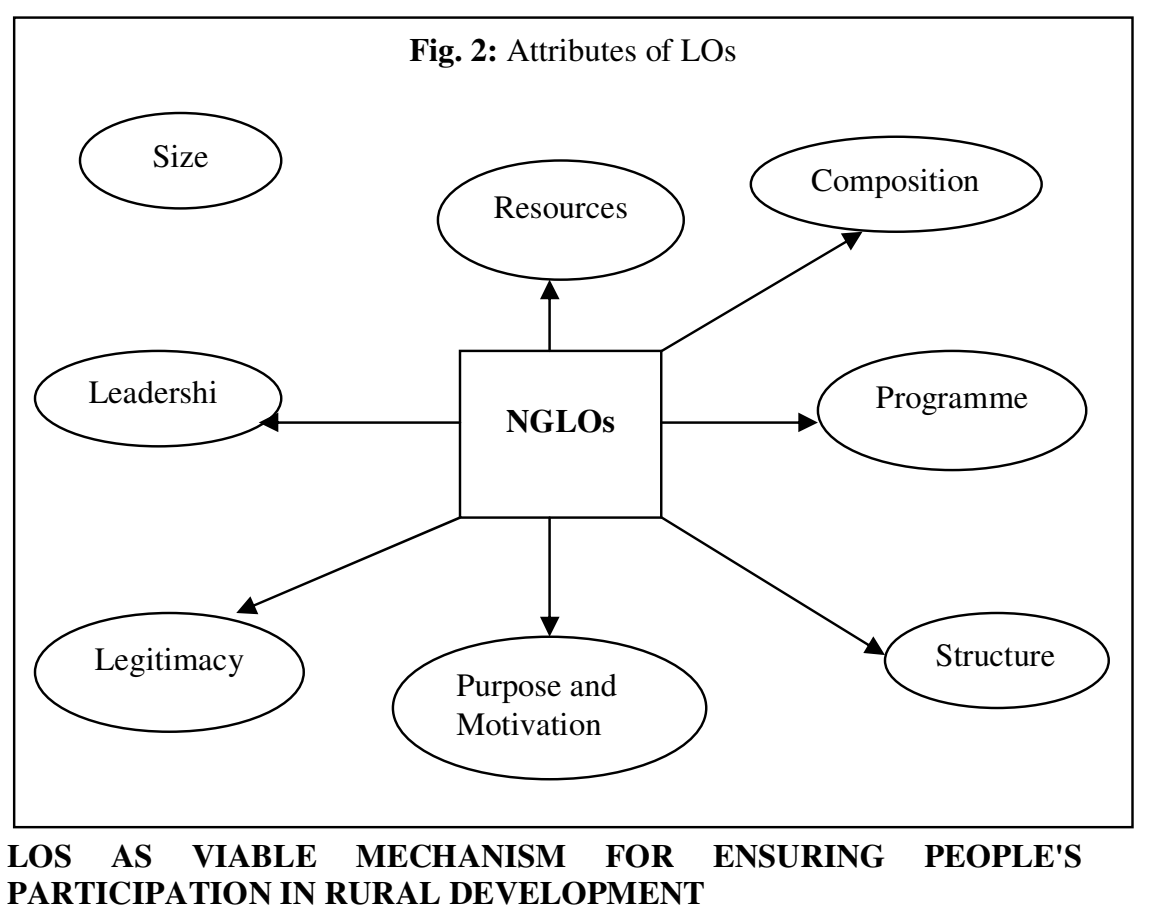

The term 'participation' includes the people's involvement in the entire decision making process. It is possible only through the people's own organization and through self- organized action. It is universally accepted and advocated that without community involvement and participation, development initiatives, either in the economic or social sector, have little chance of success, especially at the grass-root level where the majority of the population resides (Asian Productivity Organization, 1994).

At the national and regional level, participation will be more indirect i.e. through representatives, while at the local or grass-root level, more direct. Likewise, at the local level participation should be seen both as the tool and goal of development as it serves as a medium of social transformation and as a prerequisite for meaningful development. Given the existing socio-economic and political structure of the society, in most of the developing countries the so called 'representatives' of the people are most likely to represent the rich rather than the interest of the rural poor (Yadav, 1980 Quoted in Mishra; Sharma and Sharma 1984). It is obvious that an equitable sharing of benefits of development by the poor is possible when there is equitable participation by them in the process of development. By doing so, the people can influence the decisions at the higher levels through their joint efforts and common voice. This may be termed as 'bottom up' approach to rural development (Mishra, Sharma \& Sharma 1984). People's willingness and capacity to participate are essential factors in determining the effectiveness of public participation in any situation. People's willingness to participate 


\section{LOCAL ORGANIZATIONS: VIABLE MECHANISM...}

will depend on whether they have the capacity to undertake the task, whether they consider that such participation will benefit them (FAO, 1985).

The participation of people can ensure effective utilization of available resources. If the local resources however- both human and materials are utilized on the basis of decisions taken by the people themselves, the realization grows that many problems faced by people have local solutions at their levels. With active involvement of the local people, it is possible to break the mentality of dependence and also to increase their awareness, self-confidence and central of the development process. Indeed, the involvement in decision-making, implementation and monitoring through grass-root organizations helps in developing local human resources.

People's participation can be a important means of ensuring the flow of the benefits to the target groups. Experience has shown that development interventions from the externally assisted projects fail to sustain the required level of development activity once support or inputs are diminished or withdrawn by the funding agencies. People's participation is regarded as an essential prerequisite for the continuity of the activities. The involvement of local people and the utilization of existing local resources generate a sense of ownership over the development interventions to people. This sense of ownership is essential for the sustainability of the interventions even after external funds cease to flow (Kumar, 2002).

If a development program is need- based people participate in every stage of planning processes-decision making, implementation, benefit sharing and evaluation because they know it is in their own interest. It is obvious that the government machinery alone cannot successfully implement development programs, especially at the grass-root level, as it requires whole- hearted cooperation. No development strategy can be successful unless it is supported by the various social organizations that make up the target population.

Fig. 3: Four kinds of Participation

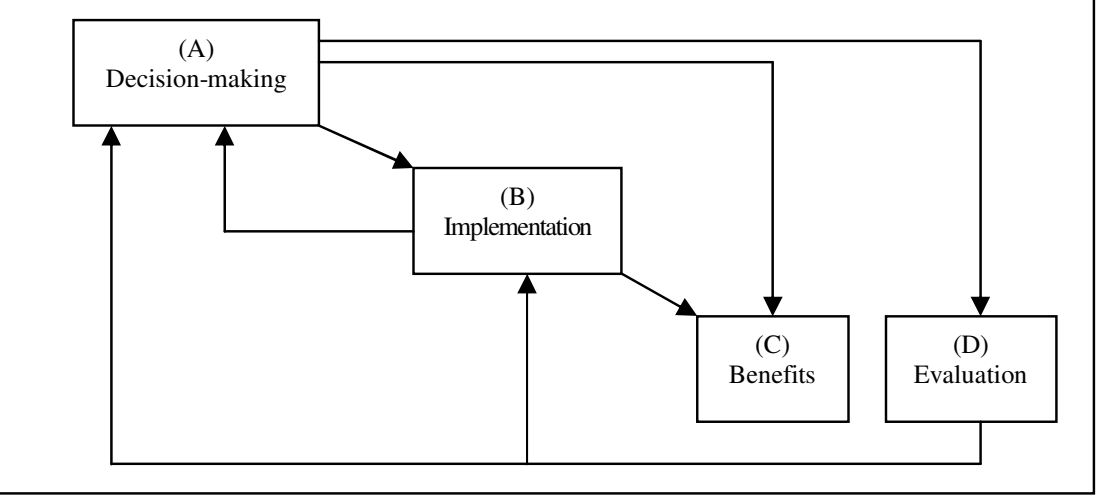

In a stratified society like Nepal if we want active participation of the people in rural development various interest based people's organizations at the local level should be formed so that more and more voices can be heard through 
more and more instititions. Basically rural area of Nepal is characterized by extreme poverty and as the poor are a heterogeneous group and some are harder to reach than others, oranizations have varying capacities to work with people living in different conditions of poverty. Local organizations give poor people a mechanism for participation. We must be careful, however, that these organzations do not become taken over by local powers.

\section{CONCLUSION}

The accelerating rural development activities need opportunities to rural people to manage their own affairs to influence public decisions and to participate in activities that affect their quality of life. People's involvement is essential for conducting broad-based rural development. For sustaining such involvement requires some configuration of organizations that are accountable and responsive to their members. LOs can provide better alternaticve in this regard. Variety of LOs even in the same area can successfully represent the variety of interest and needs of rural efficient development, by minimizing wastage, by optimally allocating resources to meet local needs, and by complementing government's own efforts to rural development. Participatory processes through local groups, therefore, also lead to greater productivity at local levels. In addition to these, local development can be initiated and sustained through organized efforts of the local people. Without better organization structure of LOs, however, achieving this goal remains successful failure.

\section{WORKS CITED}

APO. 1994. Rural Development Policies and Strategies. A Report of an APO Seminar $14^{\text {th }}-22^{\text {nd }}$ September 1993. Islamabad, Pakistan. Tokyo: Asian Productivity Organization.

Bongartz, H. 1992. Development Theories: NGOs and Self-Help Organizations. Kathmandu: Nepal Foundation for Advanced Studies (NEFAS).

Curtis, D. 1991. Beyond Government Organizations for Common Benefit. London: Macmillan Education Ltd.

Dale, R. 2004. Evaluating Development Programmes and Projects. Second Edition. New Delhi: Sage Publications.

ESCAP. 1979. Guidelines for Rural Centre Planning. New York. United Nations.

Esman, M. J. \& Uphoff, N.T. 1984. Local Organizations: Intermediaries in Rural Development . Ithaca: Cornell University Press.

FAO. 1985. Towards Improved Multi- level Planning for Agriculture and Rural Development in Asia and the Pacific. FAO. Economic and Social Development Paper 52. Rome: Food and Agriculture Organization of the United Nations.

Hayami, Y. 2001. Development Economics from the Poverty to the Wealth of Nations. Second Edition. New York: Oxford University Press. 
Korten, D.C. (1980). "Community Organization and Rural Organization and Rural Development: A Learning Process approach". Public Administration Review. 40(5), pp. 480-511.

Kumar, S. 2002. Methods for Community Participation: A Complete Guide for Practitioners, New Delhi: Vistaar Publications.

Mishra, S.N, Sharma, N. \& Sharma, K. 1984. Participation and Development. Delhi: NBO Publishers Distributors.

Narayansuwami, C. 1991. "Institution Building for Development Lessons Learned and Tasks Ahead". Asian Development Review. Vol. 9. No. 2. Manila: Asian Development Bank, pp. 137-155.

Shams, K. 1987. "Organizing Local Level Initiatives for Decentralized Rural Development. The Regional Experience." Building from Below: Local Initiatives for Decentralized Development in Asia and Pacific. Anil Bhat and others. Vol. 1, Malaysia: Asian and Pacific Development Centre (APDC), pp. 107-142.

Uphoff, N.T. 198). Local Institution Development: An Analytical Sourcebook with Cases. Connecticut: Kumarial Press.

Uphoff, N.T. 1987. "An Introduction to institution Building: What it is, What It Can do". Institution Building and Development. CEDA Study Series, Seminar Paper No. 1 (June 26-30). Kathmandu: Center for Economic Development and Administration (CEDA), Tribhuvan University Campus. pp. 21-25.

World Bank. 2004. Development and Poverty Reduction: Looking Back, Looking Ahead. Washington: The World Bank. 